\title{
Predictability of aortic dissection as a function of aortic diameter
}

\author{
G. SÜTSCH*, R. JENNI* L. von SEGESSER † AND M. TURINA† \\ From the ${ }^{*}$ Departments of Internal Medicine, Cardiology, and of $†$ Cardiovascular Surgery, University Hospital, \\ Zürich, Switzerland
}

KEY WORDS: Dissection of ascending aorta, echocardiography and aortic dissection, aortic diameter and dissection.

The role of aortic diameter on the occurrence of type A dissection was investigated in 73 patients with dilated ascending aorta at the time of pre-operative evaluation. Using transthoracic echocardiography for diagnosis and measurements, 54 patients were identified with type A dissection (group 1) and 19 without dissection (group 2). The true mean aortic diameters were identical $(6.0 \pm 1.3 \mathrm{~cm}$ in group 1 and $6.4 \pm 1.4 \mathrm{~cm}$ in group $2 ;$ mean $\pm S D ; n s)$ as were the indexed aortic diameters (ratio of diameter/body surface area; $3.2 \pm 0.8 \mathrm{~cm} . \mathrm{m}^{-2}$ and $3.4 \pm 0.7 \mathrm{~cm} . \mathrm{m}^{-2}$, respectively; $n s$ ). However, the individual diameters showed a pronounced scatter in both groups (range from $3.6 \pm 11.0 \mathrm{~cm}$ ). Of the 73 patients, 66 had surgery (47/54 with and 19/19 without dissection) and seven patients were treated medically. Emergency surgery was performed in 45/66 patients (all with acute type $A$ dissection) and elective repair in 21/66 (19 without and two with chronic type A dissection). In-hospital mortality was $18 \%$ in the emergency group, $5 \%$ in the elective group and $57 \%$ in the medical group.

It is concluded that patients with dilated ascending aorta have a substantial incidence of acute dissection. Their clinical course is unpredictable: acute dissection occurs in some, and in others the ascending aorta continues to enlarge without dissection. Because patients with dissection of ten arrive too late for elective repair and have to be operated on as emergencies with a higher operative risk, we recommend elective surgery before the diameter of the ascending aorta has reached $6 \mathrm{~cm}$.

\section{Introduction}

The pathology underlying acute dissection of the ascending aorta has been widely investigated in the past $^{[1-4]}$. Some predisposing factors such as Marfan's syndrome, aortic valve malformation, systemic hypertension, familial cluster, pregnancy or aortic atherosclerosis are well documented ${ }^{[1,3-6]}$.

If sudden dissection occurs, dramatic complications may develop. These comprise severe aortic valve regurgitation, rapid antero- or retrograde progression of the dissection inducing coronary, carotid or spinal ischaemia, and pericardial effusion or intrapericardial rupture with haemorrhagic tamponade ${ }^{[1,7]}$. In these cases, surgery is mandatory since survival in patients not treated surgically is severely impaired with a mortality rate of $18 \%$ in the first $15 \mathrm{~min}, 22 \%$ in the first $6 \mathrm{~h}$ and $65-75 \%$ in the first week after the diagnosis ${ }^{[1,4,5,8,9]}$ with an overall estimate of $1 \%$ per $h$ during the first $48 \mathrm{~h}^{[10.11]}$.

However, indication for prophylactic aortic aneurysmal surgery to prevent potential dissection, as suggested for patients with Marfan's syndrome, is still debated ${ }^{[4,6.7 .12]}$. There is insufficient evidence to suggest that the diameter of the aneurysm plays a pivotal role in the occurrence of type A dissection in non Marfan patients. Nevertheless, at least two arguments advocate an elective replacement once dilatation is diagnosed. First, Laplace's law states that for a given transmural pressure, vascular wall tension

Submitted for publication on 16 July 1990 and in revised form 16 November 1990.

Correspondence: Dr G. Sütsch, MD, Department of Internal Medicine, Cardiology, University Hospital, Rämistrasse 100, CH-8091 Zürich, Switzerland. increases proportionately to the radius of the vessel ${ }^{[13]}$; therefore, progressive expansion of the ascending aorta is expected to correlate directly with an increased risk of dissection and/or rupture. Second, continuous refinement of surgical techniques and improved surgical skills have led to $a$ better prognosis in recent years ${ }^{17,9,14]}$ which, in turn justifies a more aggressive interventional policy. Consequently, the new challenge is not only to detect aortic aneurysms but also to determine the adequate timing for surgical intervention in patients at risk of acute dissection and/or rupture ${ }^{[4,6]}$

Two-dimensional echocardiography ( $2 \mathrm{D}$ echo) is a reliable and accurate tool for recognising ascending aortic dilatation and type A dissection ${ }^{[4,6,15,16]}$. This method has improved bedside diagnosis and therefore rapid decision making. As a noninvasive technique, it is also well suited for screening or for short- and/or long-term observation of patients at risk ${ }^{[4.6]}$.

The present study was designed to determine the size of the ascending aorta at the time of dissection, to evaluate whether the diameter of dilatation is correlated to age, clinical history and constitution, to establish whether these findings are predictive of dissection, and, finally, to elucidate whether survival is dependent upon the acuity of surgical repair.

\section{Methods}

\section{STUDY GROUPS}

We systematically reviewed the archives of the echocardiographic laboratory from I January 1987 to 31 December 1989 to find patients with the diagnosis of type 
(a)

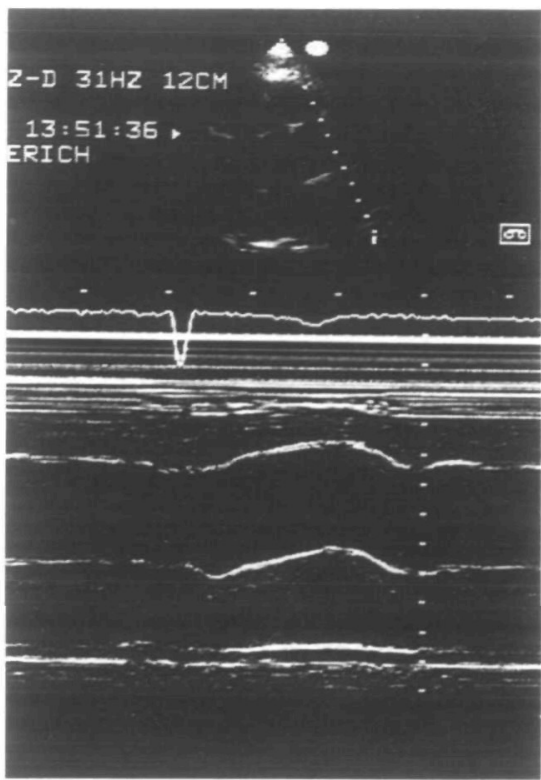

$+$

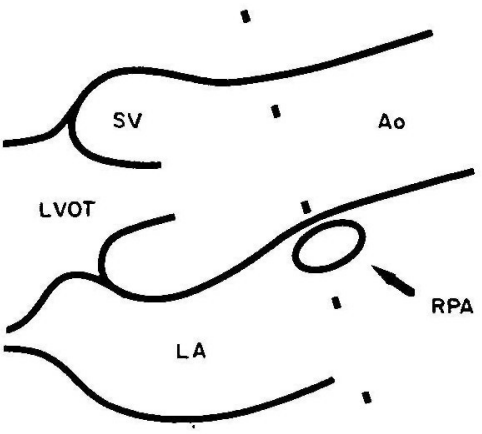

(b)

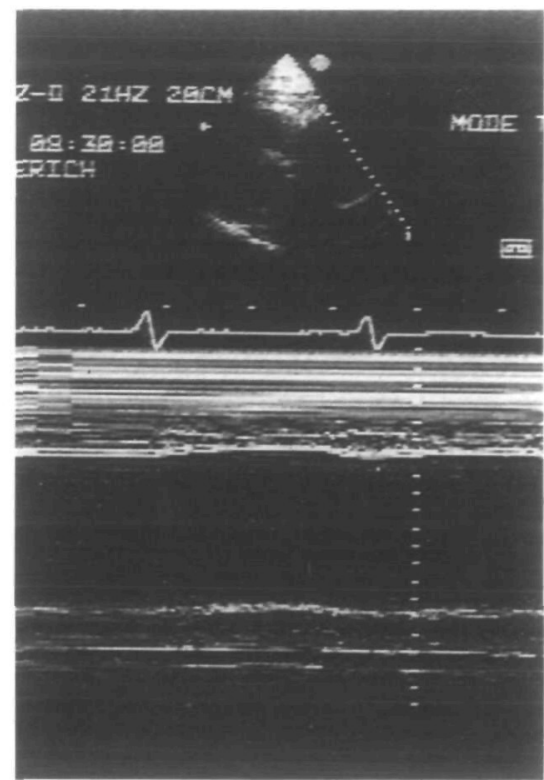

(c)

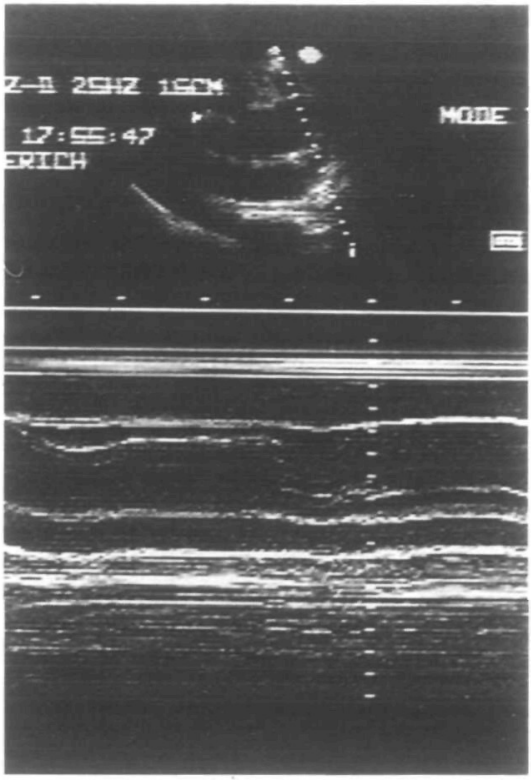

Figure I Still frames of 2-D echocardiography (upper panels) from the parasternal long-axis view in three patients (frames (a) (b) and (c)) and the corresponding target $\mathrm{M}$-mode recordings (lower panels). Frame (a) shows a normal ascending aorta with a diameter of $3 \cdot 7 \mathrm{~cm}$, frame (b) an abnormally dilated ascending aorta with a diameter of $8.8 \mathrm{~cm}$ from a patient without dissection, and frame (c) a dilated ascending aorta with a diameter of $4.7 \mathrm{~cm}$ from a patient with type $A$ dissection; note the dissection membrane in the ascending aorta in (c). The diagram indicates the site of measurement of the ascending aortic diameter at the level of the right pulmonary artery. (LVOT: left ventricular outflow tract; SV: sinus of Valsalva; LA: left atrium; Ao: aorta; RPA: right pulmonary artery).

A dissection. For the same period, we also identified all patients who had dilatation of the ascending aorta and were eligible for surgical repair of the aorta alone or in combination with a replacement of the aortic valve because of a valvular pathology. Because the purpose of the study was to evaluate the size of the ascending aorta in vivo we excluded patients who did not have complete 2 D echo visualization of the entire ascending aorta (aortic valve, sinus portion, ascending aorta and aortic arch).

The 73 patients entering the study were divided into two groups according to the diagnosis of either dilatation with dissection (type A dissection, group $1, n=54$ ) or dilatation without dissection (group 2, $n=19$ ). Echocardiographic diagnosis of presence or absence of dissection was confirmed at surgery and/or at necropsy except for three cases with type A dissection who were discharged from our hospital without surgery. In these cases, the echocardiographic diagnosis was undoubtedly enforced by clinical and radiological findings.
Dilatation of the ascending aorta was defined as a diameter at the level of the right pulmonary artery of $4.0 \mathrm{~cm}$ or more (71 cases) or as a diameter of the sinus portion over $4.0 \mathrm{~cm}$ (two cases). The normal upper limit for the ascending aorta as determined by echocardiography is $3.8 \mathrm{~cm}^{[17]}$.

Type $\mathbf{A}$ dissection was diagnosed if the ascending aorta was involved regardless of the site of the primary tear. Chronic dissection was diagnosed if the event of dissection or related symptoms were present for 2 weeks or longer. Thus, in the dissection group, 52/54 patients had an acute event and 2/54 had chronic dissection.

\section{TRANSTHORACIC ECHOCARDIOGRAPHIC TECHNIQUE AND ULTRASONIC CRITERIA FOR DIAGNOSIS}

All ultrasonic examinations were performed on a mobile Hewlett-Packard 77020 AC machine unit equipped with a duplex transducer containing a $2.5 \mathrm{MHz}$ crystal set for imaging and a $1.9 \mathrm{MHz}$ crystal set for continuous wave 
Table I Diagnosis of patients with dilatation of the ascending aorta

\begin{tabular}{lcccc}
\hline & Total & $\begin{array}{c}\text { Male } \\
\text { patients }\end{array}$ & $\begin{array}{c}\text { Female } \\
\text { patients }\end{array}$ & $\begin{array}{c}\text { Mean age; years } \\
\text { (range) }\end{array}$ \\
\hline Number of patients & 73 & 57 & 16 & $\begin{array}{c}55 \cdot 4 \pm 12 \cdot 5 \\
(15-75)\end{array}$ \\
$\begin{array}{l}\text { Group 1 } \\
\text { Dilatation with }\end{array}$ & 54 & 41 & 13 & $\begin{array}{c}54 \cdot 9 \pm 12 \cdot 8 \\
\text { Dissection }\end{array}$ \\
$\begin{array}{l}\text { Group 2 } \\
\text { Dilatation without } \\
\text { Dissection }\end{array}$ & 19 & 16 & 3 & $\begin{array}{c}56 \cdot 8 \pm 11 \cdot 7 \\
(38-75)\end{array}$ \\
\hline
\end{tabular}

Doppler. M-mode and two-dimensional echocardiograms were recorded in standard cross-sectional images on all available planes on VHS video tape.

In the acute type A dissection group, the studies were performed in the intensive care unit and included apical two and four chamber, subcostal, para- and suprasternal views. Criteria for dissection were: a double-lumen aorta separated by an intimal flap, a high-frequency oscillation of the ruptured intimal flap fluttering in the blood-stream, a thrombosed false lumen, a central displacement of an intimal calcification, and a separation of the intimal layer from the thrombus. Side-branches of the aorta were examined to visualize the extension of dissection. Pericardial effusion was assessed by echocardiography, as was left ventricular wall motion, to detect myocardial ischaemia. Aortic insufficiency was diagnosed by pulsed Doppler and/or by colour-coded Doppler signals as well as by the presence of diastolic fluttering of the mitral leaflet. Due to the emergency situation in this group, usually only one echocardiographer was involved in the bedside examination. However, all diagnoses were re-evaluated by another investigator who reviewed the video tape.

In the group without dissection and in the two cases with chronic type A dissection, echocardiographic examination was performed at the time of a pre-operative office visit according to the approach previously described.

\section{EVALUATION OF ABSOLUTE AND CORRECTED DIAMETER OF THE ASCENDING AORTA}

The cross-sectional diameters of the ascending aorta were measured by two-dimensional target $\mathrm{M}$-mode echocardiography at the level of the sinus of Valsalva, the right pulmonary artery and the aortic arch using the leading edge to leading edge convention ${ }^{[8]}$. However, in the final evaluation we included only the end-systolic dimensions of the ascending aorta at the level of the right pulmonary artery (Fig. 1). All measurements were repeated by at least two observers. For comparison between the groups, the aortic diameters were corrected by dividing the diameters by the body surface area (BSA; indexed diameter).

CLINICAL DATA AND PATHO-ANATOMICAL DEFINITIONS

All available clinical, surgical, histological and/or necropsy records were used to study the patient's age, gender and clinical history, and to obtain information about the functional and anatomical status of the aortic valve and ascending aorta, respectively. In cases where a histopathological investigation was performed, samples of the sinus portion and/or ascending aorta were routinely examined for cystic medial necrosis, elastin fragmentation, fibrosis and media-degeneration.

A diagnosis of systemic hypertension was made if there was a history of documented hypertension or of antihypertensive treatment, or if echocardiographic and/or necropsy findings were suggestive of prolonged hypertension. Presence of aortic valve disease or malformation or of annulo-aortic ectasia was evaluated by echocardiography and confirmed by surgical exploration or inspection at postmortem.

\section{SURGERY}

Surgery was performed in all patients with a nondissecting aneurysm and type A dissection (66/73) except in seven (7/73) in whom severe complications (i.e. cerebral ischaemia, paraplegia, prolonged loss of renal and visceral perfusion) or other concomitant diseases (i.e. coronary artery disease with pre-existing impaired left ventricular function or concomitant pulmonary disease) suggested a poor postoperative prognosis. In those cases a conservative treatment was applied.

The operative approach was so variable that a complete list cannot be included.

Operative mortality was defined as death occurring in the hospital regardless of the time after surgery, and inhospital mortality as death occurring during hospital stay regardless of whether or not surgery had been performed.

\section{STATISTICAL ANALYSIS}

All values are reported as mean \pm standard deviation. The unpaired Student's t-test was applied to compare the data of the two study groups; the coded chi-square test to compare the survival data (both using Stat View $512+$ package; Brain Power, Calabasa, CA, U.S.A.), and the one-tailed Fisher's 2 by 2 exact test (BMDP, Statistical Software, Los Angeles, CA, U.S.A.) to compare the data of emergency versus elective surgery (significance level $P \leqslant 0.05$ ). 
Patients with dissection
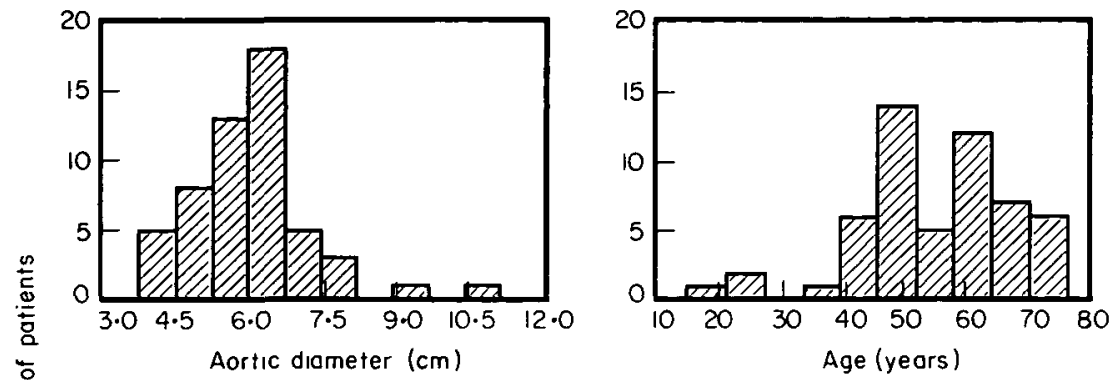

Patients without dissection
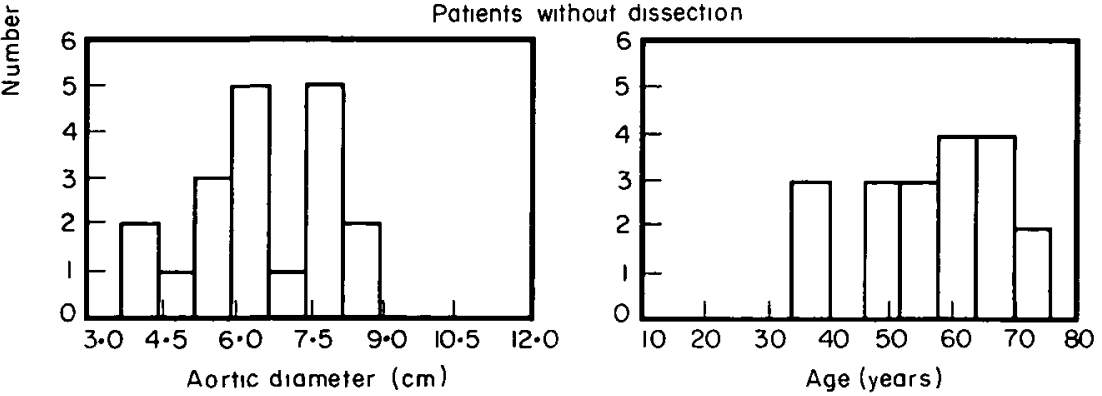

Figure 2 A histogram of ascending aortic diameter and age in the two groups (upper panels: patients with dissection; lower panels: patients without dissection).

\section{Results}

The age and sex distribution of patients with dilatation of the ascending aorta are shown in Table 1 and Fig. 2 . In group 1, type A dissection occurred in patients aged between 15 and 75 years. In spite of that wide range, the mean age $(54.9 \pm 12.8$ years $)$ did not differ from the mean age of the group without dissection $(56 \cdot 8 \pm 11 \cdot 7$ years; $n s)$. In both groups, male subjects were more numerous (total 57 males and 16 females).

Table $2(a+b)$ summarizes the clinical, cardiovascular and echocardiographic data. Height and body surface area (BSA) were identical in the two groups. The individual aortic diameters varied from 3.6 (a patient with sinus portion dilated up to $6.0 \mathrm{~cm}$ but with an otherwise normally sized ascending aorta) to $11.0 \mathrm{~cm}$. In the dissection group, the diameter of the ascending aorta varied from 3.7 to $11.0 \mathrm{~cm}$ (mean $5.96 \pm 1.26 \mathrm{~cm}$ ), whereas in the group without dissection the aortic size ranged from 3.6 to $8.2 \mathrm{~cm}$ (mean $6.41 \pm 1 \cdot 38 \mathrm{~cm}$; $\mathrm{ns}$ ). The mean value for the

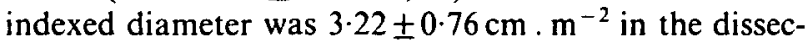
tion group and $3.43 \pm 0.69 \mathrm{~cm} \mathrm{.m^{-2 }}$ (ns) in the group without dissection. Each group included one patient with a normal ascending aortic diameter of 3.7 and 3.6 , respectively, but marked dilatation of the sinus portion ( 6.0 and $5.8 \mathrm{~cm}$, respectively). The patient with type A dissection underwent emergency surgery and the entry of the dissection was found just distal to the annulus; the patient with an intact ascending aorta had dilatation of the sinus of Valsalva and underwent elective ascending aortic repair in combination with aortic valve replacement.

An echocardiographic diagnosis of aortic insufficiency was made in 45 of the 54 patients $(83 \%)$ with type $A$ dissection and in 17 of 19 patients $(89 \%)$ without dissection (overall $85 \%$ ).
In the group with type A dissection, systemic hypertension was present in $34 / 54$ patients $(67 \%)$. Two patients (2/54) had clinical features of Marfan's syndrome, including a 27-year-old woman who experienced acute dissection in the 32 nd week of pregnancy. In the same group, three patients had a bicuspid aortic valve which, in one case (a 15-year-old boy), was associated with coarctation of the aorta. Three patients reported that other family members had a history of aortic dissection. Finally, four patients had had prior aortic valve replacement, two patients had previously received an aorto-iliac prosthesis and one patient had been submitted to a carotid endarterectomy.

In the group without dissection, $18 / 19$ patients were found to have annulo-aortic ectasia which, in all but one, was associated with aortic insufficiency. A history of systemic hypertension was present in $7 / 19(37 \%)$ patients, and aortic stenosis with asymmetric hypertrophy of the left ventricle was diagnosed in one patient.

The relationships between the diameter of the ascending aorta and age, height and BSA as well as those between the indexed diameter and age and height are shown in Fig. 3. No significant correlation was found, even after exclusion of female patients (Fig. 4).

Table 3 lists treatment and outcome in both patient groups. From the 54 patients with dissection, 45 underwent emergency and two late surgery. Seven patients were not operated on. All 19 patients in the non-dissecting group had elective surgery.

Overall in-hospital mortality was $18 \%$ ( $13 / 73$ cases). In the dissection group, $8 / 47(17 \%)$ patients died despite surgery, whereas $1 / 19$ patient $(5 \%)$ without dissection died after elective surgery. Four patients $(4 / 7,57 \%)$ with type $A$ dissection and conservative therapy died in hospital. To compare the mortality of emergency versus elective 

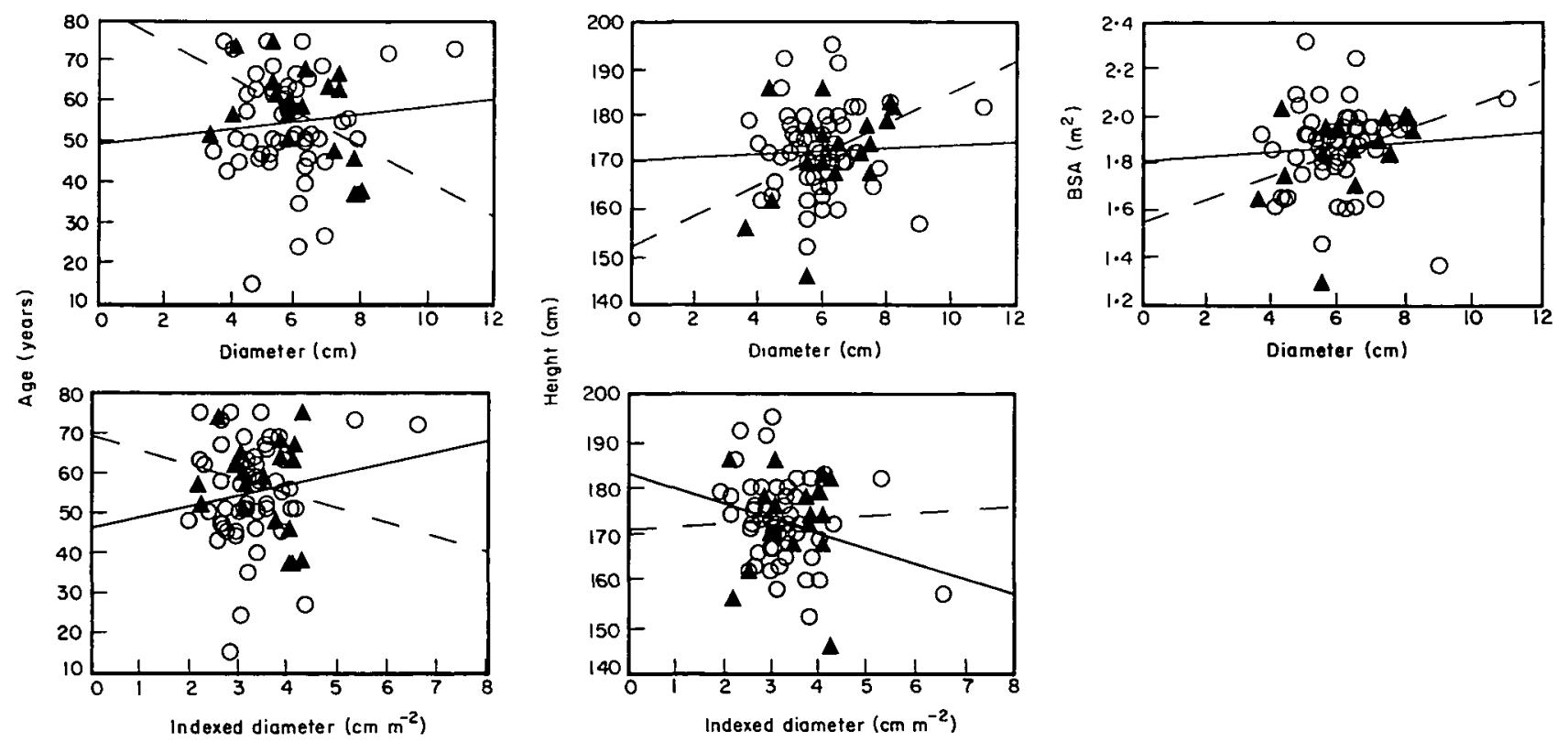

Figure 3. Relation between age, height, body surface area (BSA) and diameter of the ascending aorta for all patients ( $\mathrm{n}=73$ ). The corresponding scattergrams for the indexed diameter (aortic diameter/BSA) are shown in the lower panel. The solid lines indicate correlated data from the patients with dissection $(O)$, and the dashed lines those from the patients without dissection $(\Delta)$. ( $\mathrm{r}$ values between $0 \cdot 04$ and 0 SI, ns).
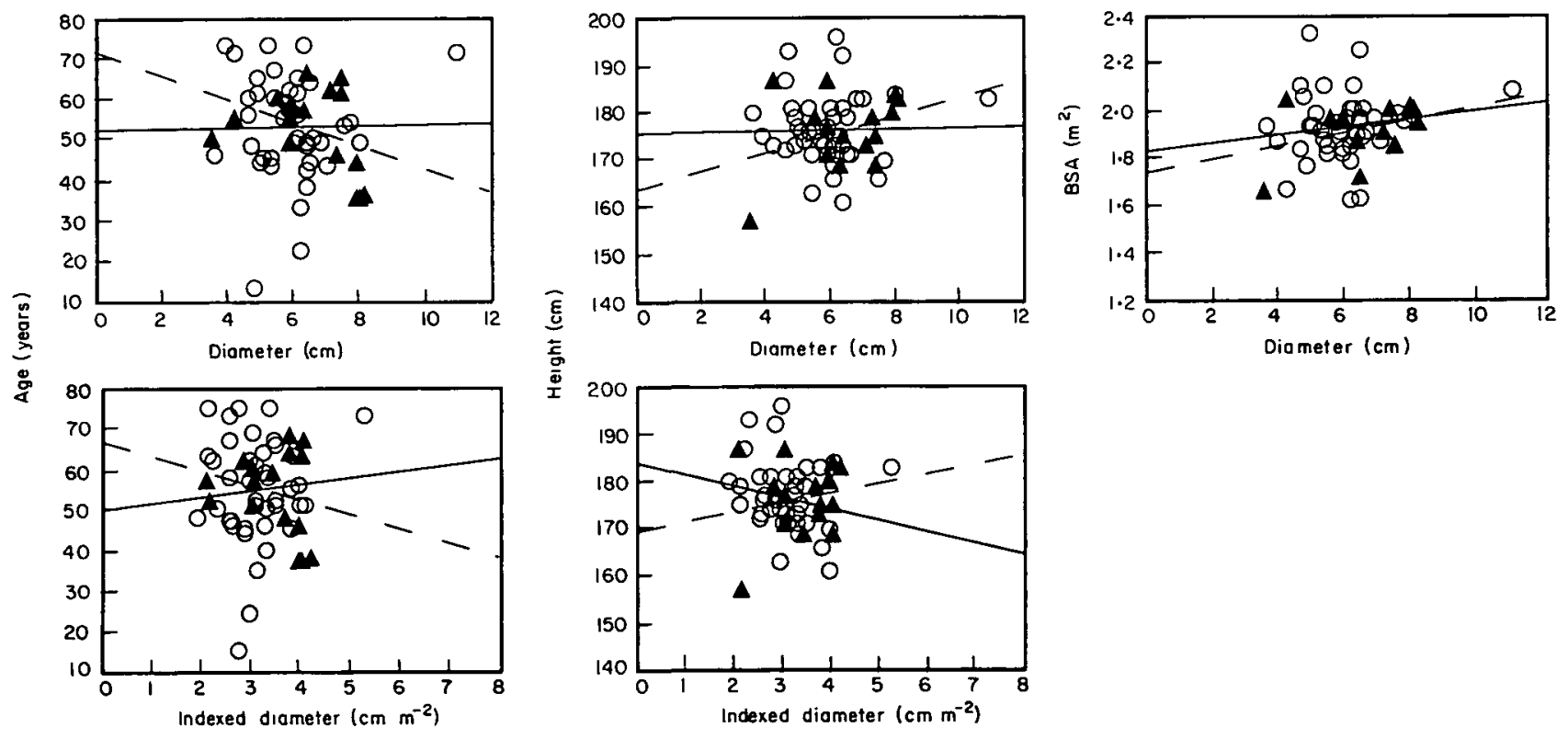

Figure 4 Same graph as Fig. 3 for male patients only $(\mathrm{n}=57$ ). No significant correlation was found ( $\mathrm{r}$ values between $0 \cdot 00$ and $0 \cdot 47, \mathrm{~ns}$ ).

operation, the two patients with chronic type A dissection were included in the elective group. Thus, the mortality in the group with emergency repair of type $A$ dissection was $8 / 45(18 \%)$ versus $1 / 21(5 \%)$ in the group with elective surgery. The coded chi-square test, however, was not significant $(P<0.3)$, probably because of the small numbers. Even if all 52 patients with acute dissection ( 12 deaths) were compared to the 21 patients with no or chronic dissection (1 death), the analysis did not show a statistically signifi- cant difference between the two groups $(P<0.057$; Fisher's exact test).

It is worth noting that the single intra-operative death in the elective group occurred in a patient in whom surgery was very delicate due to coexisting severe coronary artery disease (3-vessel disease), reduced left ventricular function (ejection-fraction: $40 \%$ ), mild to severe aortic insufficiency and significant aortic atherosclerosis. The patient finally died of cerebral complications. Interestingly, if this 
Table 2a Clinical, cardiovascular and Echocardiographic data

\begin{tabular}{|c|c|c|c|c|c|c|c|c|c|c|c|c|}
\hline Number & Sex & $\begin{array}{c}\text { Age } \\
\text { (years) }\end{array}$ & $\begin{array}{l}\text { Height } \\
(\mathrm{cm})\end{array}$ & $\begin{array}{l}\text { BSA } \\
m^{-2}\end{array}$ & $\begin{array}{l}\text { Aortic } \\
\text { size } \\
(\mathrm{cm})\end{array}$ & $\begin{array}{c}\text { Size/ } \\
\text { BSA } \\
\left(\mathrm{cm} \cdot \mathrm{m}^{-2}\right)\end{array}$ & $\begin{array}{l}\text { Dissection } \\
\text { dilatation }\end{array}$ & AAE & $\begin{array}{c}\text { Systemic } \\
\text { hypertension }\end{array}$ & Marfan & $\begin{array}{l}\text { Valve } \\
\text { disease }\end{array}$ & Remarks \\
\hline 1 & $\mathrm{~m}$ & 51 & 160 & 1.62 & $6 \cdot 5$ & 4.00 & dissect & - & - & - & $\mathrm{AI}+$ & \\
\hline 2 & $\mathrm{~m}$ & 47 & 180 & $2 \cdot 10$ & $5 \cdot 4$ & 2.57 & dissect & - & SH & - & Al,++ bicuspld & \\
\hline 3 & $\mathbf{m}$ & 15 & 180 & 1.76 & 4.9 & $2 \cdot 78$ & dissect & - & - & - & AI +/AIS/bicuspid & \\
\hline 4 & $\mathrm{~m}$ & 24 & 195 & $2 \cdot 10$ & $6 \cdot 3$ & 3.00 & dissect & AAE & - & $M$ & $\mathrm{AI}++$ & \\
\hline 5 & $\mathrm{~m}$ & 35 & 170 & $2 \cdot 00$ & $6 \cdot 3$ & $3 \cdot 15$ & dissect & - & SH & - & $\mathrm{Al}+++$ & \\
\hline 6 & $\mathbf{m}$ & 52 & 172 & $2 \cdot 00$ & $6 \cdot 2$ & $3 \cdot 10$ & dissect & AAE & - & - & $\mathrm{Al}+++$ & \\
\hline 7 & $\mathrm{f}$ & 45 & 166 & 1.66 & $4 \cdot 5$ & $2 \cdot 71$ & dissect & - & SH & - & $\mathrm{Al}++$ & \\
\hline 8 & $\mathrm{~m}$ & 50 & 172 & 1.96 & 6.5 & $3 \cdot 32$ & dissect & - & SH & - & AS & \\
\hline 9 & $\mathrm{~m}$ & 52 & 170 & 1.90 & $6 \cdot 7$ & 3.53 & dissect & - & - & - & $\mathrm{Al}+++$ & \\
\hline 10 & $\mathrm{~m}$ & 75 & 173 & 1.91 & $5 \cdot 3$ & $2 \cdot 78$ & dissect & $\mathrm{AAE}$ & $\mathrm{SH}$ & - & $\mathrm{Al}+$ & \\
\hline 11 & $\mathrm{~m}$ & 45 & 175 & 1.87 & $5 \cdot 4$ & 2.89 & dissect & - & SH & - & $\mathrm{AI}+$ & \\
\hline 12 & $\mathrm{~m}$ & 48 & 179 & 1.93 & $3 \cdot 7$ & 1.92 & dissect & - & - & - & $\mathrm{Al}++$ & Familial cluster, dilatation of sinus \\
\hline 13 & $\mathrm{~m}$ & 47 & 175 & 1.98 & $5 \cdot 2$ & 2.63 & dissect & - & SH & - & $\mathrm{AI}+$ & \\
\hline 14 & $\mathrm{~m}$ & 50 & 192 & $2 \cdot 05$ & $4 \cdot 8$ & $2 \cdot 34$ & dissect & - & SH & - & $\mathrm{Al}++$ & \\
\hline 15 & f & 51 & 163 & 1.65 & 4.4 & 2.67 & dissect & - & SH & - & $\mathrm{Al}+$ & \\
\hline 16 & $\mathrm{~m}$ & 67 & 178 & 1.78 & $6 \cdot 2$ & $3 \cdot 48$ & dissect & $\ldots$ & SH & - & $\mathrm{AI}+++$ & \\
\hline 17 & $\mathrm{f}$ & 43 & 162 & 1.62 & $4 \cdot \overline{1}$ & $2 \cdot 53$ & dissect & - & SH & - & $\mathrm{Al}+$ & \\
\hline 18 & $\mathrm{~m}$ & 44 & 191 & $2 \cdot 25$ & $6 \cdot 5$ & 2.89 & dissect & - & - & - & $\mathrm{Al}+$ & \\
\hline 19 & $\mathrm{~m}$ & 64 & 176 & 1.83 & $6 \cdot 0$ & $3 \cdot 28$ & dissect & - & - & - & $\mathrm{Al}++$ & \\
\hline 20 & $\mathrm{~m}$ & 56 & 169 & 1.95 & $7 \cdot 8$ & 4.00 & dissect & - & SH & - & $\mathrm{AI}++$ & \\
\hline 21 & $\mathrm{~m}$ & 51 & 182 & 1.96 & 6.9 & $3 \cdot 52$ & dissect & AAE & SH & - & $\mathrm{Al}++$ & Previous Y-graft operation 1984 \\
\hline 22 & $\mathrm{~m}$ & 58 & 171 & 1.83 & $4 \cdot 7$ & $2 \cdot 56$ & dissect & - & SH & - & $\mathrm{Al}+++$ & \\
\hline 23 & $\mathrm{~m}$ & 73 & 172 & 1.66 & $4 \cdot 3$ & 2.59 & dissect & AAE & - & - & - & Previous $Y$-graft operation 1988 \\
\hline 24 & $\mathrm{~m}$ & 67 & 172 & 1.93 & $5 \cdot 0$ & $2 \cdot 59$ & dissect & - & $\mathrm{SH}$ & -. & $\mathrm{AI}+$ & \\
\hline
\end{tabular}




\begin{tabular}{|c|c|c|c|c|c|c|c|c|c|c|c|c|}
\hline 25 & f & 72 & 157 & $1 \cdot 37$ & $9 \cdot 0$ & $6 \cdot 57$ & dissect & - & SH & - & $\mathrm{AI}++$ & \\
\hline 26 & f & 50 & 167 & 1.92 & $5 \cdot 7$ & 2.97 & dissect & AAE & - & - & $\mathrm{AI}+$ & \\
\hline 27 & $\mathrm{~m}$ & 45 & 182 & 1.86 & $7 \cdot 1$ & $3 \cdot 82$ & dissect & - & - & - & $\mathrm{Al}++$ & Chronic dissection \\
\hline 28 & $\mathrm{f}$ & 69 & 152 & 1.46 & 5.5 & 3.77 & dissect & AAE & $\mathrm{SH}$ & - & $\mathrm{Al}+$ & \\
\hline 29 & $\mathrm{f}$ & 62 & 165 & 1.79 & 5.9 & $3 \cdot 30$ & dissect & - & SH & - & $\mathrm{AI}++$ & \\
\hline 30 & $\mathrm{~m}$ & 51 & 180 & 1.96 & 6.1 & $3 \cdot 11$ & dissect & AAE & SH & - & $\mathrm{AI}+++$ & \\
\hline 31 & $\mathrm{~m}$ & 51 & 183 & 1.97 & $8 \cdot 1$ & $4 \cdot 11$ & dissect & - & - & - & - & Aortic valve replacement 1974 \\
\hline 32 & $\mathrm{~m}$ & 57 & 173 & 1.94 & 5.8 & $2 \cdot 99$ & dissect & AAE & SH & - & $\mathrm{Al}++$ & Familial cluster \\
\hline 33 & $\mathrm{~m}$ & 46 & 178 & $2 \cdot 00$ & 6.6 & $3 \cdot 30$ & dissect & - & - & - & $\mathrm{AI}++$ & \\
\hline 34 & m & 59 & 170 & 1.81 & $6 \cdot 0$ & 3.31 & dissect & - & SH & - & $\mathrm{Al}+$ & Familial cluster \\
\hline 35 & $\mathrm{~m}$ & 62 & 162 & 1.84 & $5 \cdot 5$ & 2.99 & dissect & - & SH & - & $\mathrm{Al}+$ & \\
\hline 36 & $\mathrm{~m}$ & 63 & 178 & $2 \cdot 32$ & $5 \cdot 0$ & $2 \cdot 15$ & dissect & - & SH & - & - & \\
\hline 37 & $\mathrm{~m}$ & 69 & 170 & 1.81 & $5 \cdot 5$ & 3.04 & dissect & - & SH & - & $\mathrm{Al}+$ & \\
\hline 38 & $f$ & 59 & 163 & 1.90 & $6 \cdot 0$ & $3 \cdot 16$ & dissect & - & SH & - & $\mathrm{Al}+$ & \\
\hline 39 & $\mathrm{~m}$ & 62 & 186 & $2 \cdot 10$ & $4 \cdot 7$ & $2 \cdot 24$ & dissect & - & - & - & $\mathrm{Al}+$ & Aortic valve replacement 1987 \\
\hline 40 & r & 58 & 160 & 1.62 & 6.0 & $3 \cdot 70$ & dissect & - & SH & - & - & \\
\hline 41 & $\mathbf{m}$ & 40 & 180 & 1.95 & 6.5 & $3 \cdot 33$ & dissect & - & - & - & bicuspid & \\
\hline 42 & $\mathrm{~m}$ & 66 & 170 & 1.88 & 6.6 & $3 \cdot 51$ & dissect & - & SH & - & - & Aortic valve replacement 1986 \\
\hline 43 & $\mathrm{~m}$ & 55 & 165 & 1.98 & 76 & $3 \cdot 84$ & dissect & - & $\mathrm{SH}$ & - & $\mathrm{AI}++$ & \\
\hline 44 & $f$ & 51 & 167 & 1.81 & $5 \cdot 5$ & $3 \cdot 04$ & dissect & - & - & - & - & After carotid surgery 1987 \\
\hline 45 & $\mathrm{~m}$ & 63 & 165 & 1.61 & $6 \cdot 2$ & 3.85 & dissect & - & - & - & $\mathrm{AI}+++$ & \\
\hline 46 & $\mathrm{~m}$ & 61 & 172 & 1.90 & 5.9 & $3 \cdot 10$ & dissect & - & SH & - & $\mathrm{Al}+++$ & Chronic dissection \\
\hline 47 & $\mathbf{m}$ & 75 & 174 & 1.89 & $6 \cdot 4$ & 3.39 & dissect & - & SH & - & $\mathrm{Al}+$ & \\
\hline 48 & $\mathrm{~m}$ & 58 & 168 & 1.84 & $6 \cdot 2$ & $3 \cdot 37$ & dissect & - & SH & - & $\mathrm{Al}+$ & \\
\hline 49 & f & 69 & 172 & 1.96 & $7 \cdot 0$ & 3.57 & dissect & AAE & SH & - & $\mathrm{Al}++$ & \\
\hline 50 & $f$ & 63 & 158 & $1 \cdot 77$ & $5 \cdot 5$ & $3 \cdot 11$ & dissect & - & - & - & $\mathrm{Al}++$ & \\
\hline 51 & $\mathrm{~m}$ & 73 & 182 & $2 \cdot 08$ & 11.0 & $5 \cdot 29$ & dissect & - & - & - & - & Aortic valve replacement 1972 \\
\hline 52 & r & 27 & 172 & 1.65 & $7 \cdot 1$ & $4 \cdot 30$ & dissect & AAE & - & $\mathbf{M}$ & $\mathrm{AI}++$ & Dissection during pregnancy \\
\hline 53 & $\mathbf{m}$ & 46 & 176 & 1.93 & $5 \cdot 1$ & $2 \cdot 64$ & dissect & - & SH & - & $\mathrm{Al}+$ & \\
\hline 54 & $\mathrm{~m}$ & 75 & 174 & 1.86 & $4 \cdot 0$ & $2 \cdot 15$ & dissect & - & SH & - & $\mathrm{Al}+$ & \\
\hline $\begin{array}{l}\text { mean } \\
\pm S D\end{array}$ & & $\begin{array}{c}54.9 \\
\pm 12.8\end{array}$ & $\begin{array}{c}173 \\
\pm 8.8\end{array}$ & $\begin{array}{l}1.87 \\
\pm 0.2\end{array}$ & $\begin{array}{l}5.96 \\
\pm 1.3\end{array}$ & $\begin{array}{l}3.22 \\
\pm 0.8\end{array}$ & & & & & & \\
\hline
\end{tabular}


Tahle $2 b$ (linical, cardiovascular and Echocardiographic data (continued)

\begin{tabular}{|c|c|c|c|c|c|c|c|c|c|c|c|c|}
\hline Number & Sex & $\begin{array}{c}\text { Age } \\
\text { (years) }\end{array}$ & $\begin{array}{l}\text { Height } \\
(\mathrm{cm})\end{array}$ & $\begin{array}{l}\text { BSA } \\
\mathrm{m}^{2}\end{array}$ & $\begin{array}{l}\text { Aortic } \\
\text { size } \\
(\mathrm{cm})\end{array}$ & $\begin{array}{c}\text { Size/ } \\
\text { BSA } \\
\left(\mathrm{cm}^{2} \cdot \mathrm{m}^{2}\right)\end{array}$ & $\begin{array}{l}\text { Dissection } \\
\text { dilatation }\end{array}$ & AAE & $\begin{array}{c}\text { Systemic } \\
\text { hypertension }\end{array}$ & Marfan & $\begin{array}{l}\text { Valve } \\
\text { disease }\end{array}$ & Remarks \\
\hline 1 & $\mathrm{~m}$ & 57 & 170 & 1.95 & $6 \cdot 0$ & 3.08 & dilatation & $\mathrm{AAE}$ & SH & - & $\mathrm{AI}+++$ & \\
\hline 2 & $\mathrm{~m}$ & 43 & 168 & 1.85 & $7 \cdot 5$ & $4 \cdot 05$ & dilatation & $\mathrm{AAE}$ & $\mathrm{SH}$ & - & $\mathrm{AI}++$ & \\
\hline 3 & $\mathrm{f}$ & 75 & 146 & $1 \cdot 30$ & $5 \cdot 5$ & $4 \cdot 23$ & dilatation & AAE & - & - & $\mathrm{AS} / \mathrm{Al}+$ & \\
\hline 4 & $\mathrm{~m}$ & 52 & 156 & 1.65 & $3 \cdot 6$ & $2 \cdot 18$ & dilatation & $\mathrm{AAE}$ & - & - & $\mathrm{Al}+++$ & Dilatation of sinus \\
\hline 5 & $\mathrm{~m}$ & 64 & 172 & 1.90 & $7 \cdot 2$ & 3.79 & dilatation & $\mathrm{AAE}$ & SH & - & $\mathrm{AI}+++$ & \\
\hline 6 & $\mathrm{~m}$ & 68 & 174 & 1.71 & 6.5 & $3 \cdot 80$ & dilatation & AAE & - & - & $\mathrm{Al}+++$ & \\
\hline 7 & $\mathrm{~m}$ & 60 & 186 & 1.96 & 6.0 & 3.06 & dilatation & $\mathrm{AAE}$ & - & - & $\mathrm{Al}++$ & \\
\hline 8 & $\mathrm{~m}$ & 62 & 178 & 1.96 & $5 \cdot 6$ & $2 \cdot 86$ & dilatation & $\mathrm{AAE}$ & - & - & $\mathrm{AS} / \mathrm{Al}++$ & \\
\hline 9 & $\mathrm{f}$ & 74 & 162 & 175 & $4 \cdot 4$ & $2 \cdot 51$ & dilatation & - & $\mathrm{SH}$ & - & AS/ASH & \\
\hline 10 & $\mathrm{~m}$ & 67 & 174 & 1.84 & $7 \cdot 5$ & 4.08 & dilatation & AAE & - & - & $\mathrm{Al}+++$ & \\
\hline II & $\mathrm{m}$ & 46 & 179 & 2.01 & $8 \cdot 0$ & 3.98 & dilatation & $\mathrm{AAE}$ & - & - & $\mathrm{AI}++$ & \\
\hline 12 & $\mathrm{~m}$ & 51 & 176 & 1.96 & $6 \cdot 0$ & 3.06 & dilatation & $\mathrm{AAE}$ & $\mathrm{SH}$ & - & $\mathrm{AI}+++$ & \\
\hline 13 & $\mathrm{~m}$ & 48 & 178 & $2 \cdot 00$ & $7 \cdot 4$ & $3 \cdot 70$ & dilatation & $\mathrm{AAE}$ & - & - & $\mathrm{AI}++$ & \\
\hline 14 & $f$ & 65 & 170 & 1.85 & $5 \cdot 5$ & 2.97 & dilatation & $\mathrm{AAE}$ & $\mathrm{SH}$ & - & $\mathrm{AS} / \mathrm{Al}+$ & \\
\hline 15 & $\dot{\mathrm{m}}$ & 37 & 179 & $2 \cdot 00$ & $8 \cdot 0$ & 4.00 & dilatation & $\mathrm{AAE}$ & - & - & $\mathrm{Al}+$ & \\
\hline 16 & $\mathrm{~m}$ & 37 & 183 & $2 \cdot 00$ & $8 \cdot 1$ & 4.05 & dilatation & AAE & - & - & $\mathrm{Al}+++$ & \\
\hline 17 & $\mathrm{~m}$ & 59 & 168 & 1.86 & $6 \cdot 4$ & 3.44 & dilatation & $\mathrm{AAE}$ & $\mathrm{SH}$ & - & - & \\
\hline 18 & $\mathrm{~m}$ & 57 & 186 & $2 \cdot 04$ & $4 \cdot 3$ & $2 \cdot 11$ & dilatation & $\mathrm{AAE}$ & - & - & $\mathrm{Al}+++$ & \\
\hline 19 & $\mathrm{~m}$ & 38 & 182 & 1.94 & $8 \cdot 2$ & $4 \cdot 23$ & dilatation & AAE & - & - & $\mathrm{Al}+++$ & \\
\hline $\begin{array}{l}\text { mean } \\
\pm \mathrm{SD}\end{array}$ & & $\begin{array}{l}56.8 \\
\pm 11.6 \\
\mathrm{~ns}\end{array}$ & $\begin{array}{c}173 \\
\pm 10 \cdot 2 \\
\mathrm{~ns}\end{array}$ & $\begin{array}{c}1.87 \\
\pm 0.2 \\
\text { ns }\end{array}$ & $\begin{array}{c}6.4 I \\
\pm I-4 \\
\mathrm{~ns}\end{array}$ & $\begin{array}{c}3.43 \\
\pm 0 \cdot 7 \\
\text { ns }\end{array}$ & & & & & & \\
\hline
\end{tabular}

m: male, f: female; Aortic size: diameter of the ascending aorta at the level of the right pulmonary artery; Size/BSA: ratio of the diameter of the ascending aorta and BSA: AAE: annuloaortic ectasia; SH: systemic hypertension: M: Marfan`s syndrome; Al: aortic valve insufficiency $(+=$ mild, $++=$ moderate. $+++=$ severe); AIS: coarctation of the aorta: bicuspid: bicuspid aortic valve; AS: aortic valve stenosis; ASH: asymmetric septal hypertrophy.

ns: not significant means group 1 versus group 2. 
Table 3 Diagnosis, therapeutic and surgical management of patients with and without dissection

\begin{tabular}{|c|c|c|c|c|c|c|}
\hline \multirow{2}{*}{ Group I } & \multirow[t]{2}{*}{$\begin{array}{l}\text { Number of } \\
\text { patients }\end{array}$} & \multirow[t]{2}{*}{$\begin{array}{l}\text { Conservative } \\
\text { treatment }\end{array}$} & \multirow[t]{2}{*}{$\begin{array}{l}\text { Surgical } \\
\text { treatment }\end{array}$} & \multicolumn{2}{|c|}{$\begin{array}{l}\text { In-hospital } \\
\text { mortality } \\
\text { conservative/ } \\
\text { surgical }\end{array}$} & \multirow[t]{2}{*}{$\begin{array}{c}\text { No } \\
\text { follow-up }\end{array}$} \\
\hline & & & & & & \\
\hline Acute dissection & 52 & 7 & 45 & 4 & 8 & 3 \\
\hline Chronic dissection & 2 & - & 2 & - & - & - \\
\hline \multicolumn{7}{|l|}{ Group 2} \\
\hline $\begin{array}{l}\text { Dilatation without } \\
\text { dissection }\end{array}$ & 19 & - & 19 & 一 & 1 & - \\
\hline Total & 73 & 7 & 66 & 4 & 9 & 3 \\
\hline
\end{tabular}

Table 4 Histological examination in patients with dilatation of the ascending aorta

\begin{tabular}{|c|c|c|c|c|c|c|}
\hline & $\begin{array}{l}\text { Medial necrosis } \\
\text { (Erdheim-Gsell) }\end{array}$ & $\begin{array}{c}\text { Mucoid } \\
\text { degeneration }\end{array}$ & Arteriosclerosis & $\begin{array}{l}\text { Normal } \\
\text { findings }\end{array}$ & $\begin{array}{c}\text { No } \\
\text { histology }\end{array}$ & $\begin{array}{c}\text { Percentage } \\
\text { with histology }\end{array}$ \\
\hline \multicolumn{7}{|l|}{ Group 1} \\
\hline $\begin{array}{l}\text { Dilatation with } \\
\quad \text { dissection }(n=54)\end{array}$ & 13 & 15 & 3 & 2 & 21 & 61 \\
\hline \multicolumn{7}{|l|}{ Group 2} \\
\hline $\begin{array}{l}\text { Dilatation without } \\
\text { dissection }(n=19)\end{array}$ & 10 & - & I & 4 & 4 & 79 \\
\hline Total $(n=73)$ & 23 & 15 & 4 & 6 & 25 & 66 \\
\hline
\end{tabular}

patient had not been operated on, the statistical analysis of survival of all emergency versus all elective cases would have shown a statistical significance with a $P$ value $<0.015$ ( 12 deaths out of 52 patients versus no death out of 20 patients).

Of the seven patients with type A dissection who had no surgery, early follow-up was not available in three cases because they had been discharged from our institution.

A histological examination was performed in $33 / 47$ patients with, and in 15/19 without, dissection (Table 4). In the group with type A dissection, medial necrosis (Erdheim-Gsell) was found in 13 patients and mucoid degeneration in 15. Arteriosclerosis was reported in three cases and a normal aortic wall was found in two patients. In the group without dissection, the histological examination revealed medial necrosis in 10 cases; one patient showed arteriosclerosis and four had a normal microscopic study.

\section{Discussion}

The effect of surgical treatment on the survival of patients with type A dissection has been previously demonstrated ${ }^{[7,9,14]}$ but only a few publications have raised the question of the possible role of the diameter of the aneurysmal ascending aorta on the occurrence of type A dissection $^{[4,6,10]}$. Our results substantiate the role of aneurysmal diameter on dissection and add further support to the ideas that aortic surgery should be envisaged early in patients with dilatation of the ascending aorta. In this study, the echocardiographic examination of the ascending aorta in patients with type A dissection revealed the presence of ascending aortic dilatation with a mean diameter of $6 \mathrm{~cm}$ at the time of dissection. The aortic diameters, however, were widely scattered and ranged from $3.7 \mathrm{~cm}$ (including a patient with dissection at the level of the sinus portion but, otherwise, a normal sized ascending aorta) up to $11 \mathrm{~cm}$. This finding underrates the limitations of an enlarged aortic diameter to predict the occurrence of aortic dissection. In addition, the mean aortic diameter in the group without dissection was slightly, albeit not significantly, larger $(6.4 \mathrm{~cm})$ than that of the dissection group $(6.0 \mathrm{~cm})$, and the individual values also scattered although not quite so widely. The aortic dimensions ranged in this group from 3.6 (on a patient with dilated sinus portion of $6.0 \mathrm{~cm}$ ) to $8.2 \mathrm{~cm}$. A comparable, large distribution of the values of the ascending aorta diameter has been described in a population of patients with Marfan's disease ${ }^{[6]}$. The aneurysmal diameter of the ascending aorta, measured by echocardiography, varied from 5.6 to $10 \mathrm{~cm}$ (mean $7.4 \mathrm{~cm}$ ) in the dissection group (14 patients) and from 5.3 to $9.0 \mathrm{~cm}$ (mean $6.9 \mathrm{~cm}$ ) in the group without dissection (36 patients) ${ }^{[6]}$. This variability is therefore not surprising and other reports have confirmed it ${ }^{[4,6,10,12]}$.

The decision to perform preventive aortic surgery is easy in the presence of marked dilatation, but is difficult when the ascending aorta is moderately dilated. In the latter condition, there is no apparent need for operation, but dissection of the ascending aorta may obviously occur even with a mild degree of dilatation. This has been shown in patients with manifest Marfan's syndrome. To prevent 
the possible severe complications resulting from dissection, some clinicians and surgeons advocate preventive surgical repair when the diameter of the ascending aorta exceeds $5.5 \mathrm{~cm}^{[7]}$; others even routinely operate when the aortic size is above $5 \mathrm{~cm}^{[6,12]}$. The cardiovascular complications resulting from Marfan's syndrome usually occur at a younger age; they generally constitute a different entity because of concomitant cardiovascular and systemic problems. In this condition, early surgical treatment may be even more justified ${ }^{[6.12]}$.

Some of our patients without dissection had an ascending aorta similarly dilated, or even larger, than in the dissection group. These patients underwent preventive surgical repair of their aortic lesion before the occurrence of any acute complication. Admittedly, the majority of these patients were either symptomatic or had clinical evidence of an underlying aortic pathology which made the diagnosis of dilatation easier and, therefore, referral to a cardiovascular surgeon faster.

The major advantage of elective versus emergency surgery is the improved survival rate in patients in whom surgery can be planned and performed on schedule ${ }^{[4,14]}$. Recently, survival of patients with lesions of the ascending aorta was shown to correlate with the extent and degree of pre-operative problems and complications; it is inversely proportional to the severity of symptoms ${ }^{[9.12]}$. Mortality in the setting of emergency surgery varies from $32-41 \%{ }^{[1.4,14]}$ whereas, in cases of elective surgery it is about 8 $10 \%{ }^{[1,4,14]}$. Our results are in accordance with these figures although our mortality rates are much higher than those of the Standford group who report an operative mortality of $7 \%$ in a series of 31 patients with acute type A dissection $^{[7]}$. Surprisingly, the repair of chronic type A dissection in that study was associated with a mortality of $11 \%$; one would have expected a lower operative morality than in acute dissection because chronic patients have already survived the most critical phase.

In our analysis, and with the exception of preexisting dilatation, we were unable to detect any characteristic feature that could have been responsible for the recurrence of type A dissection, though, systemic hypertension deserves attention. It was found to be a major risk factor in a postmortem study of 161 cases $^{[2]}$ and was diagnosed in $67 \%$ of our patients. Although it is an unspecific marker, one should stress that it was encountered in only $39 \%$ of the patients with no dissection.

A newly discovered aortic regurgitant murmur associated with typical chest pain often raises the suspicion of an acute dissection: these features facilitate fast diagnosis of type A dissection. Presence of aortic regurgitation can usually be confirmed by 2D Doppler-echocardiography and is found in 51 to $78 \%$ of cases at the time of admission $^{[1.5 .7 .15]}$. The high incidence of aortic regurgitation in our study ( $83 \%$ in patients with dissection) must be interpreted keeping in mind that we included all patients who had valvular insufficiency regardless of the severity. On the other hand, a large proportion $(89 \%)$ of the patients without dissection also had aortic regurgitation but, in this group, the insufficency was mainly caused by annulo-aortic ectasia $(95 \%)$.
2D echo has demonstrated reliability and accuracy for the detection of aortic dissection (sensitivity: 79$99 \%{ }^{[15.16]}$; predictive accuracy: $91 \%{ }^{116]}$. Transesophageal echocardiography is a new tool for detection of aortic disease and is best indicated for type $\mathrm{A}$ and $\mathrm{B}$ dissection ${ }^{[19]}$. In some rare cases, a discordance between the clinical and the echocardiographic findings may become apparent; in these cases we suggest the use of a third diagnostic method (angiography, CT).

\section{References}

[1] Jex RK, Schaff HV, Piehler JM et al. Repair of ascending aortic dissection J Thorac Cardiovasc Surg 1987; 93: 375-84.

[2] Larson EW, Edwards WD. Risk factors for aortic dissection: a necropsy study of 161 cases. Am J Cardiol 1984; 53: 849-55.

[3] Nicod P, Bloor C. Godfrey $M$ et al. Familial aortic dissecting aneurysm. J Am Coll Cardiol 1989, 13: 81 1-9.

[4] Bruno L, Prandi M, Colombi P, La Vecchia L. Diagnostic and surgical management of patients with aneurysms of the thoracic aorta with various causes $\mathrm{Br}$ Heart J 1986; 55: 81-91

[5] Anagnostopoulos CE, Prabhakar MJ, Kittle CF Aortic dissections and dissecting aneurysms. Am J Cardiol 1972; 30: 263-73.

[6] Gott VL, Pyeritz RE, Magovern GJ, Cameron DE, McKusick VA. Surgical treatment of aneurysms of the ascending aorta in the Marfan syndrome. N Engl J Med 1986; 314: 1070-4

[7] Miller DC, Mitchell RS, Oyer PE, Stinson EB, Jamieson SW, Shumway NE. Independent determinants of operative mortality for patients with aortic dissections Circulation 1984, 70 (Suppl. I): 153-64.

[8] Egloff L, Baumann PC, Studer $M$ et al. Die chirurgische Behandlung des dissezierenden Aortenaneurysmas Typ I und II. Schweiz Med Wochenschr 1985; 115. 1295-9.

[9] Chirillo F, Marchior1 MC, Andriolo L et al. Outcome of 209 patients with aortic dissection. A 12-year multicentre experience. Eur Heart J 1990; 11: 311-9.

[10] Miller DC. Surgical management of aortic dissectıons. Indications, perioperative management, and long-term results. In: Doroghazi RM, Slater EE, eds. Aortic dissection. New York: McGraw-Hill, 1983; 193-243.

[11] Jamieson WRE, Munro AI, Miyagishima RT, Allen P, Tyers GFO, Gerein AN. Aortıc dissections. Early diagnosis and surgical management are the keys to survival. Can J Surg 1982; 25. $145-9$.

[12] Svensson LG, Crawford ES, Cosellı JS, Safi HJ, Hess KR. Impact of cardiovascular operation on survival in the Marfan patient. Circulation 1989; 80 (Suppl 1): 233-42.

[13] Laplace PS. Théorie de l'action capillaire. In: Traité de la mécanique céleste. Paris: Courcier, 1823; 5 (Suppl. X).

[14] Galloway AC, Colvin SB, LaMendola CL et al. Ten-year operative experience with 165 aneurysms of the ascending aorta and aortic arch. Circulation 1989; 80 (Suppl I). 249-56.

[15] Erbel R, Daniel W, Visser C, Engberding R, Roelandt J, Rennollet H. Echocardiography in diagnosis of aortic dissection. Lancet 1989; 1: 457-63.

[16] Khandheria BK, Tajik AJ, Taylor CL et al. Aortic dissection: Review of value and limitations of two-dimensional echocardiography in a six-year experience. J Am Soc Echo 1989; 2: 17-24

[17] Huntsman LL, Stewart DK. Barnes SR. Franklın SB. Colocousis JS, Hessel EA. Noninvasive Doppler determination of cardiac output in man. Clinical validation. Circulation 1983; 67: 593-602.

[18] Gardin JM, Tobis JM, Dabestianti A et al. Superiority of twodimensional measurement of aortic vessel diameter in Doppler echocardiographic estimates of left ventricular stroke volume. J Am Coll Cardiol 1985; 6: 66-74.

[19] Bansal RC, Shakudo M, Shah, PM, Shah PM. Biplane transesophageal echocardiography: technique, image orientation, and preliminary experience in 131 patients. J Am Soc Echo 1990; 3: 348-66. 